\title{
SUPERMAGIC GRAPHS HAVING A SATURATED VERTEX $^{1}$
}

\author{
Jaroslav IVANČO AND TAtiana Polláková \\ Institute of Mathematics, \\ P.J. Šafárik University \\ Jesenná 5, 04154 Košice, Slovakia \\ e-mail: jaroslav.ivanco@upjs.sk \\ tatiana.pollakova@student.upjs.sk
}

\begin{abstract}
A graph is called supermagic if it admits a labeling of the edges by pairwise different consecutive integers such that the sum of the labels of the edges incident with a vertex is independent of the particular vertex. In this paper we establish some conditions for graphs with a saturated vertex to be supermagic. Inter alia we show that complete multipartite graphs $K_{1, n, n}$ and $K_{1,2, \ldots, 2}$ are supermagic.
\end{abstract}

Keywords: supermagic graph, saturated vertex, vertex-magic total labeling.

2010 Mathematics Subject Classification: 05C78.

\section{REFERENCES}

[1] L. Bezegová and J. Ivančo, On conservative and supermagic graphs, Discrete Math. 311 (2011) 2428-2436.

doi:10.1016/j.disc.2011.07.014

[2] J.A. Gallian, A dynamic survey of graph labeling, Electron. J. Combin. 18 (2011) \#DS6.

[3] J. Ivančo, On supermagic regular graphs, Math. Bohem. 125 (2000) 99-114.

[4] J. Ivančo, Magic and supermagic dense bipartite graphs, Discuss. Math. Graph Theory $27(2007) 583-591$. doi:10.7151/dmgt.1384

\footnotetext{
${ }^{1}$ The work was supported by the Slovak Research and Development Agency under the contract No. APVV-0023-10 and by the Slovak VEGA Grant 1/0652/12.
} 
[5] J. Ivančo, A construction of supermagic graphs, AKCE Int. J. Graphs Comb. 6 (2009) 91-102.

[6] J. Ivančo and T. Polláková, On magic joins of graphs, Math. Bohem. (to appear).

[7] J. Ivančo and A. Semaničová, Some constructions of supermagic graphs using antimagic graphs, SUT J. Math. 42 (2006) 177-186.

[8] J.A. MacDougall, M. Miller, Slamin and W.D. Wallis, Vertex-magic total labelings of graphs, Util. Math. 61 (2002) 3-21.

[9] J. Sedláček, Problem 27. Theory of Graphs and Its Applications, Proc. Symp. Smolenice, Praha (1963) 163-164.

[10] A. Semaničová, Magic graphs having a saturated vertex, Tatra Mt. Math. Publ. 36 (2007) 121-128.

[11] B.M. Stewart, Magic graphs, Canad. J. Math. 18 (1966) 1031-1059. doi:10.4153/CJM-1966-104-7

[12] W.D. Wallis, Magic Graphs (Birkhäuser, Boston - Basel - Berlin, 2001). doi:10.1007/978-1-4612-0123-6

Received 21 May 2012

Revised 13 November 2012

Accepted 14 November 2012 